\title{
Ungewohntes Umdenken
}

\author{
Silke Brockmann \\ Swissmedic, Schweizerisches Heilmittelinstitut, Bern, Schweiz
}

Ich stimme Herrn Judin [1] dahingehend zu, dass die Begrifflichkeit und damit auch die Abgrenzung von Komplementärund Alternativmedizin (CAM) zur «Schulmedizin» oder besser gesagt zur «konventionellen Medizin» nicht klar definiert bzw. ständig im Fluss ist.

Allerdings empfinde ich seine Differenzierung «Eine Therapie wirkt entweder auf die Ursache der Erkrankung oder auf die Mechanismen der Krankheitsentwicklung oder auf beides» auch nicht als ausreichend.

Mein Einwand ist: Das Besondere an Lebewesen ist - im Unterschied zu Maschinen -, dass sie über die Möglichkeit der Selbstheilung verfügen. Eine Therapie kann also auch eine bloße Förderung der Selbstheilung sein und braucht nicht unbedingt an der Ursache oder an den Mechanismen der Krankheitsentstehung anzugreifen.

Weitere «levels of disease» und die daraus folgenden verschiedenen Interventionsmöglichkeiten wurden von Zollman und Vickers [2] sehr anschaulich zusammengefasst (Abb. 1).
Die evidenzbasierte Medizin lässt sich gar nicht in diese Klassifizierungsschemata einordnen. Für sie ist weder die Ätiopathogenese, also die Kausalität einer Erkrankung, noch die Ebene der Intervention noch der Grund für eine Besserung oder Heilung interessant. Die evidenzbasierte Medizin interessiert nur, $o b$ etwas wirksam ist oder nicht. Das damit verbundene Umdenken ist für «konventionell» ausgebildete Ärztinnen und Ärzte - zu denen auch ich gehöre - das eigentlich Schwierige.

\section{Literatur}

Judin E: «Back to the roots» oder eine Alternative zu den Begriffen Schulmedizin und CAM. Forsch Komplementmed 2011;18:106-107.

2 Zollman C, Vickers A: What is complementary medicine? BMJ 1999;319:693696.
Abb. 1. Reproduced from Zollmann C, Vickers A: ABC of complementary medicine: What is complementary medicine? BMJ 2011; 319:693-696. Reproduced with permission. (c) BMJ Publishing Group Ltd.

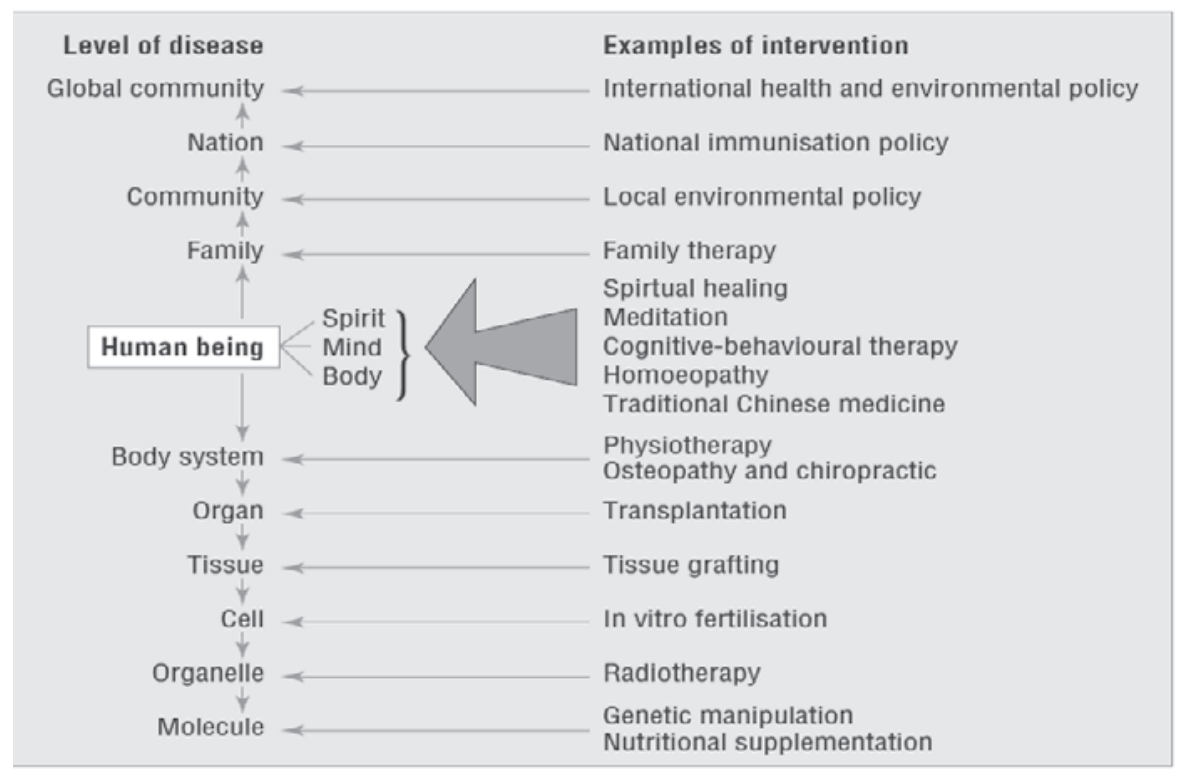

\begin{tabular}{|c|c|}
\hline KARGER & $\begin{array}{l}\text { (c) } 2011 \text { S. Karger GmbH, Freiburg } \\
1661-4119 / 11 / 0184-0219 \$ 38.00 / 0\end{array}$ \\
\hline $\begin{array}{l}\text { Fax +49 } 7614520714 \\
\text { Information@Karger.de } \\
\text { www.karger.com }\end{array}$ & $\begin{array}{l}\text { Accessible online at: } \\
\text { www.karger.com/fok }\end{array}$ \\
\hline
\end{tabular}

